\title{
TINJAUAN SISTEM INFORMASI AKUNTANSI UMKM BERBASIS CLOUD
}

\author{
Rahadian Prilahardo \\ Program Studi Akuntansi \\ Fakultas Ekonomi Universitas Katolik Darma Cendika \\ Jalan Dr. Ir. H. Soekarno 201, Surabaya
}

\begin{abstract}
The purpose of this study is to identify considerations of acquiring Cloud based Accounting Information System as Software as a Service (SaaS) towards small to medium businesses which has evolve alongside information technology revolution by comprehensively review basic concept of cloud computing and flexibility and agility values added by cloud computing onto conventional Accounting Information System thus may change the decision making process for small to medium business owners and management. This study provides comprehensive review of Cloud-based Accounting Information System and Non-cloud for small and medium business.
\end{abstract}

\begin{abstract}
ABSTRAK
Tujuan dari penelitian ini adalah untuk mengidentifikasi pertimbanganpertimbangan menggunakan Sistem Informasi Akuntansi berbasis Cloud sebagai Software as a Service (SaaS) untuk usaha kecil dan menengah, di mana telah berevolusi bersama revolusi teknologi informasi dengan cara komprehensif meninjau konsep dasar cloud computing dan nilai tambahnya berupa fleksibilitas dan kelincahan untuk Sistem Informasi Akuntansi konvensional hingga kemudian dapat mengubah proses pengambilan keputusan pemilik dan manajemen usaha kecil dan menengah. Studi ini memberikan tinjauan komprehensif Sistem Informasi Akuntansi berbasis Cloud dan Non-Cloud untuk usaha kecil dan menengah
\end{abstract}

Keywords: cloud computing, software as a service, cloud based accounting.

\section{PENDAHULUAN}

Perkembangan teknologi informasi dalam menyentuh berbagai bidang di segala aspek meningkat begitu pesat. Menurut Syaikhu (2010) saat ini keberadaan teknologi informasi telah mengubah perilaku pengguna dalam mencari dan memilih informasi yang mereka butuhkan. Pengguna membutuhkan kecepatan dan ketepatan akses di mana dan kapan saja melalui perangkat yang dimilikinya. Cloud Computing atau Komputasi Awan (KA) adalah pemicu berubahnya perilaku tersebut. Pertama kali implementasi dalam bisnis diperkenal- 


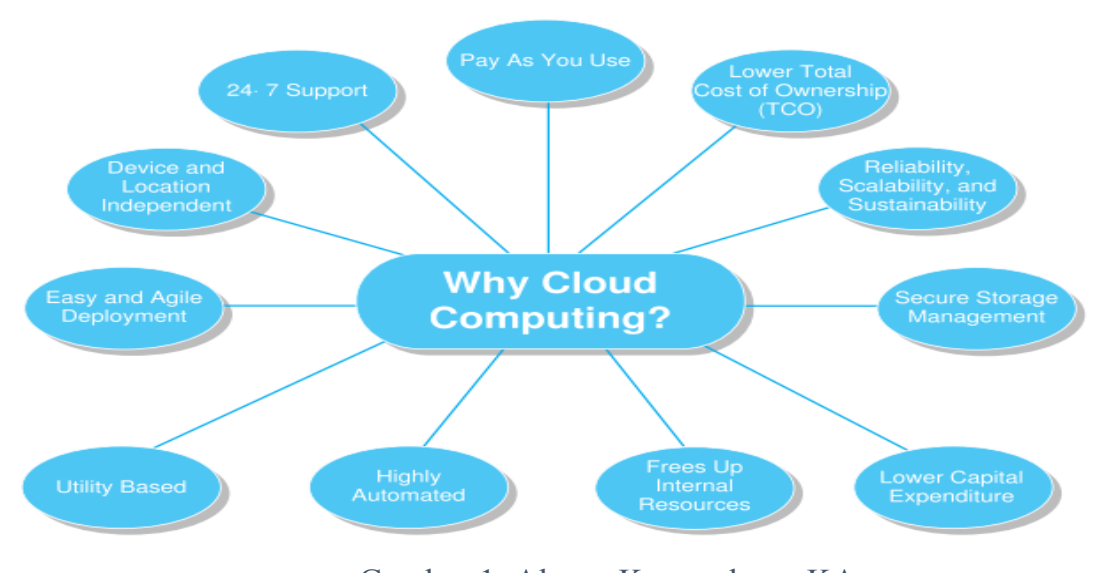

Gambar 1 Alasan Kepopuleran KA

kan Salesforce.com pada tahun 1999 kemudian Amazon tahun 2002 hingga Google tahun 2009 terus mengalami lompatan-lompatan dan perkembangan yang luar biasa.

Menurut Stieningera et al. (2014) KA kemudian disebut sebagai cara baru untuk memberikan teknologi informasi layanan kepada individu dan organisasi. Difusi dan adopsi komputasi awan terutama di kalangan organisasi didorong melalui ketersediaan publik layanan cloud yang memberikan manfaat ganda seperti peningkatan fleksibilitas dan kelincahan (Gambar 1). Kekuatan fleksibilitas dan kelin- cahan KA dapat membantu pertumbuhan bisnis karena pengembangan yang cepat dan tidak diperlukannya biaya investasi besar sesuai definisi, karakteristik dan model-model deployment KA.

Potensi jasa-jasa yang disediakan dalam lingkungan KA (Software as A Service, Platform as A Service dan Infrastructure as A Service) secara total menurut Castellina (2014) dalam situs Forbes menyebutkan peningkatan pengeluaran yang luar biasa dalam kurun waktu sepuluh tahun diperkirakan sama-sama naik hingga $450 \%$ untuk ketiga jenis layanan tersebut.

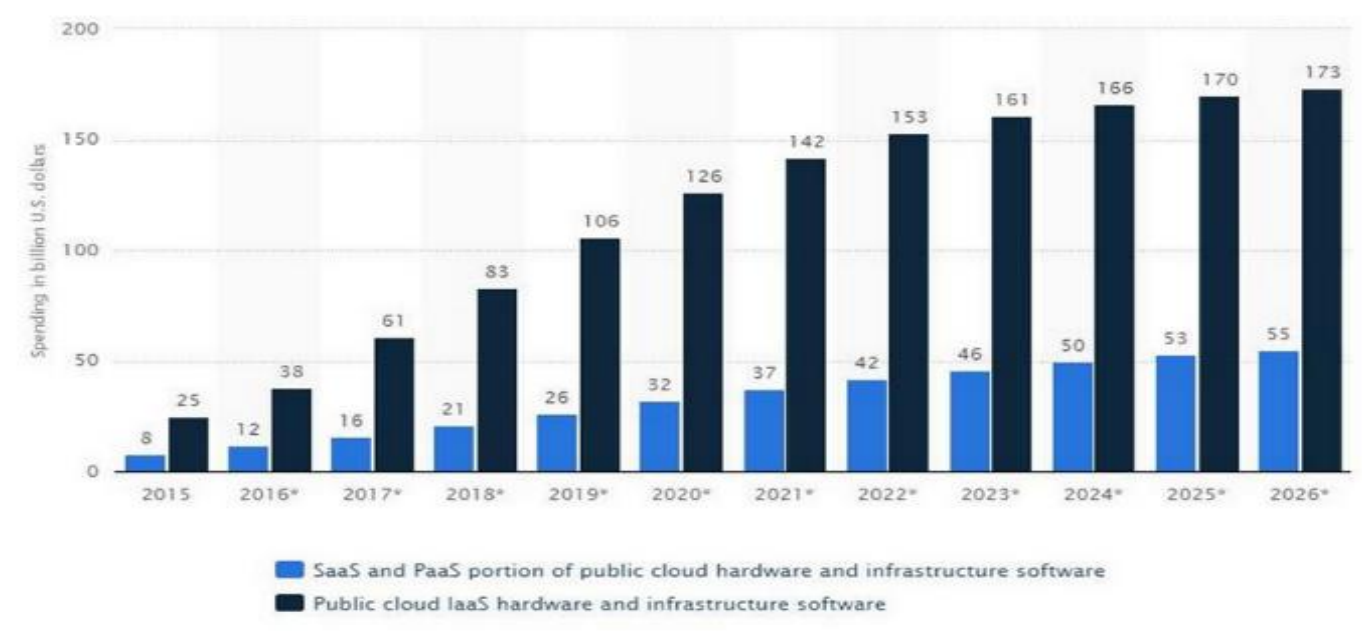




\section{TINJAUAN PUSTAKA Komputasi Awan}

Mell and Grance (2011) merekomendasikan definisi dan karakteristik KA serta model deployment secara lengkap yang kemudian dimasukkan dalam National Institute of Standards and Technology Special Publication Nomor 800-145. Publikasi tersebut menyebutkan definisi KA, "cloud computing is a model for enabling ubiquitous, convenient, on-demand network access to a shared pool of configurable computing resources (e.g., networks, servers, storage, applications, and services) that can be rapidly provisioned and released with minimal management effort or service provider interaction".

Kata kunci dalam definisi tersebut yang berhubungan dengan fleksibilitas adalah "on-demand" dan "configurable resources" di mana organisasi bisa memilih hanya menggunakan fitur-fitur yang benar-benar diperlukan dan mengkonfigurasinya sesuai kebutuhan. Sedangkan kata kunci "rapidly provisioned" dan "minimal management effort or interaction" berhubungan dengan kelincahan KA di mana organisasi dengan segera mengimplementasikan fiturfitur yang diperlukan dengan usaha/interaksi yang minimal.

Kemudian KA disebutkan memiliki lima karakteristik penting yaitu on-demand self-service di mana pengguna dapat dengan mudah mengaktifkan dan menonaktifkan fitur sesuai parameter yang diinginkan, broad network access di mana pengguna mendapatkan akses yang luas bahkan multi-platforms tidak hanya di PC tetapi juga perangkat mobile, resource pooling yang memungkinkan pemusatan sumber daya infrastruktur sesuai kebutuhan organisasi. Rapid elasticity memungkinkan pengalokasian sumber daya yang memadai secara cepat dan measured service di mana pengguna dapat menetapkan ukuran atau parameter yang jelas sebagai batasan atau pengalokasian fitur-fitur secara otomatis. KA juga disebutkan memiliki tiga bentuk layanan: Software as a Service (SaaS) adalah jasa aplikasi dari pihak

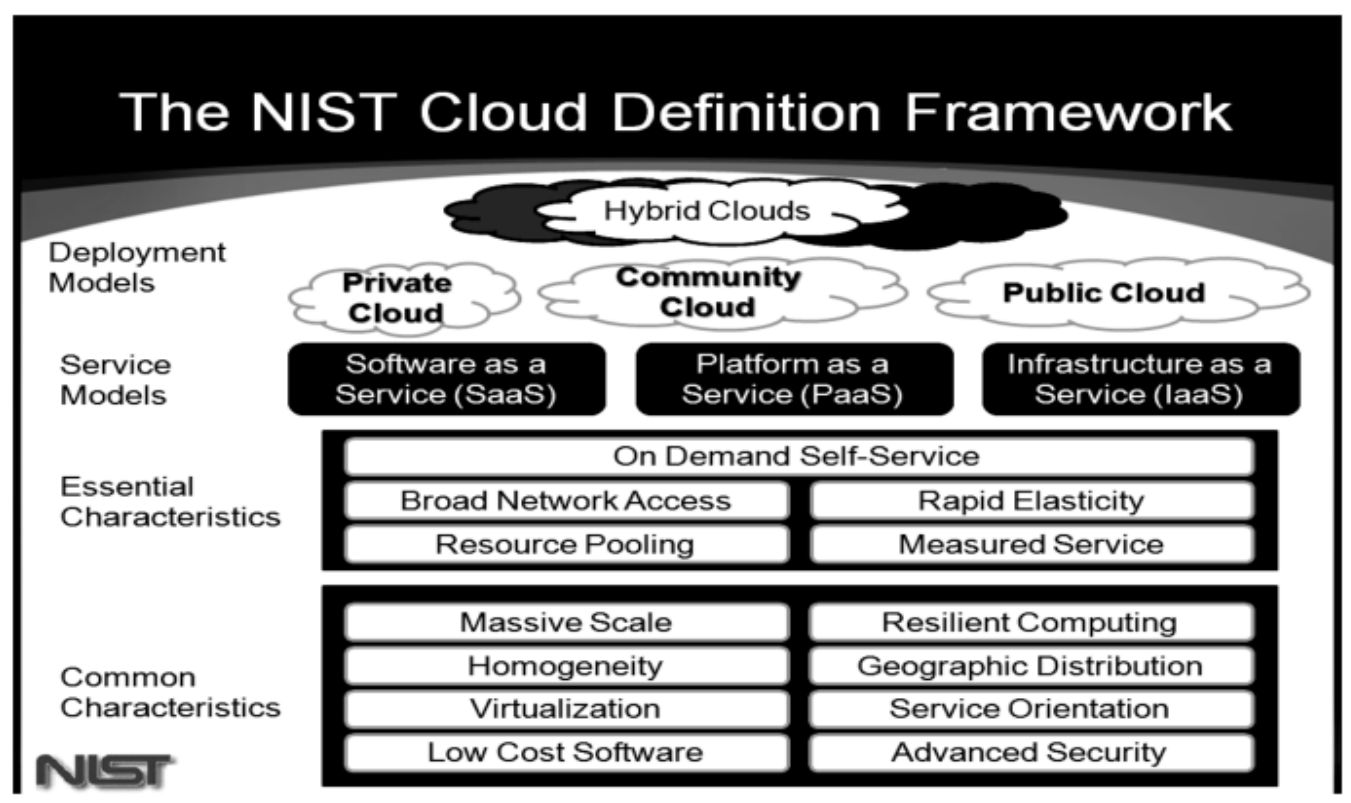

Gambar 3 - Definisi KA oleh NIST 
ketiga yang berjalan di lingkungan Cloud, Platform as a Service (PaaS) adalah jasa penyediaan pelantar (platform) untuk aplikasi milik organisasi yang dijalankan di lingkungan Cloud dan Infrastructure as a Service (IaaS) adalah jasa penyediaan infrastruktur Cloud yang sepenuhnya dikendalikan oleh organisasi (Gambar 3).

Sementara KA memiliki empat model penyebaran (deployment) yaitu Private Cloud adalah model penyebaran eksklusif hanya untuk satu organisasi, Community Cloud khusus untuk suatu komunitas yang terdiri dari beberapa organisasi, Public Cloud adalah penyebaran terbuka atau non-eksklusif dan Hybrid Cloud penyebaran kombinasi antara model penyebaran satu dengan yang lain.

\section{Keuntungan Adopsi KA}

Simkin et al. (2012) menandaskan bahwa sepintas KA seperti hanya menawarkan fungsi-fungsi yang ditawarkan oleh baik piranti lunak SIA (Sistem Informasi Akuntansi) yang diimplementasikan secara lokal dalam organisasi maupun alih daya pemrosesan seluruh transaksi dalam suatu siklus akuntansi kepada pihak ketiga. Perbedaan utamanya adalah keunggulan-keunggulan yang semakin banyak bagi organisasi yang mengadopsi KA dan semakin efisien seiring perkembangan teknologi informasi (Gambar 4).

\section{Faktor-faktor Pengaruh Adopsi KA} Stieningera et al. (2014) menyebutkan lima faktor pertimbangan suatu organisasi mengadopsi KA sebagai berikut:

1. Compatibility.

a. Data Exchangeability, kemudahan mengambil data dari KA.

b. Process Integrability, kemampuan mengintegrasikan berbagai proses dalam organisasi.

c. Vendor Interoperability, menggunakan standar-standar yang berlaku luas, sehingga memudahkan proses migrasi dan integrasi.

2. Relative Advantage.

a. Usefulness, kemampuan penyelesaian masalah dibanding solusi non-KA.

b. Quality, perbaikan yang dihasilkan dibanding solusi non-KA.

c. Convenience, keunggulan relatif dalam kenyamanan pengoperasian.

d. Costs, biaya dibanding keunggulan relatifnya.

\begin{tabular}{|c|c|}
\hline Advantage & Example \\
\hline $\begin{array}{l}\text { Access to specialized } \\
\text { expertise }\end{array}$ & $\begin{array}{l}\text { In a payroll application, the vendor keeps up to date with the most recent } \\
\text { tax-withholding requirements. }\end{array}$ \\
\hline Cost savings & $\begin{array}{l}\text { The contracting company avoids the hardware, software, and training costs } \\
\text { involved in performing the service in house, and pays only for the services } \\
\text { actually consumed. }\end{array}$ \\
\hline Speed & $\begin{array}{l}\text { In a tax-preparation application, all communications take place electron- } \\
\text { ically and therefore nearly instantaneously, thereby avoiding the data- } \\
\text { transfer delays in, say, post-office options. }\end{array}$ \\
\hline Access to distant vendors & $\begin{array}{l}\text { In an e-mail application, the least costly vendor might be thousands of miles } \\
\text { away-a factor of no consequence to the contracting company. }\end{array}$ \\
\hline $\begin{array}{l}\text { Avoiding peak loading } \\
\text { problems }\end{array}$ & $\begin{array}{l}\text { Sales often spike during the Christmas season. The retailer offloads these } \\
\text { volume problems to the vendor. }\end{array}$ \\
\hline Virtual remote backup & $\begin{array}{l}\text { A company makes a copy of its critical data at the same time it updates } \\
\text { the initial database. This increases security because the backup copy is by } \\
\text { definition off-premises. }\end{array}$ \\
\hline Pay as you go & $\begin{array}{l}\text { The outsourcing company avoids the initial investments in hardware, soft- } \\
\text { ware, or personnel. This can be similar to the difference between owning a } \\
\text { car and renting a taxi. }\end{array}$ \\
\hline
\end{tabular}

Gambar 4 Keunggulan Komputasi Awan 
e. Speed, kecepatan yang dalam penerapannya bisa berupa kecepatan koordinasi, komunikasi dan sebagainya.

f. Performance, kinerja terukur dalam hal membantu organisasi memudahkan operasional.

3. Complexity.

a. Frustration, tingkat kesulitan pengoperasian.

b. Flexibility, form antar muka yang tidak kaku.

c. Task Adequacy, kemudahan dalam menyelesaikan tugas.

d. Expectation Conformity, perila$\mathrm{ku}$ sistem sesuai yang diharapkan.

4. Image.

a. Reputation of the cloud service provider, reputasi penyedia jasa KA.

b. Reputation of the innovation, reputasi solusi/produk yang dihasilkan penyedia jasa KA.

c. Innovatiness, keinovatifan produk/jasa penyedia jasa KA.

5. Security and Trust.

a. Data security, keamanan data dan fasilitasnya.

b. Trustfulness of the cloud service provider, penyedia jasa yang dapat dipercaya.

c. Contractual agreements, perjanjian tertulis.

d. Geographical location, kedekatan lokasi di mana bisa berpengaruh pada legalitas entitas dan kemudahan pelayanan purna jual.

\section{Akuntansi Tradisional versus Cloud Accounting}

Dalam presentasinya Phillips (2012) secara singkat menyajikan empat generasi aplikasi akuntansi dan membagi mereka menjadi tiga periode utama, seperti yang akan dijelaskan berikut ini:

1. Kurun 90-an' didominasi oleh kategori pertama software akuntansi, dicap sebagai era "Windows", ditandai dengan aplikasi yang padat namun mudah digunakan, penting bagi semua klien, terlepas dari besar kecilnya. Fitur yang paling menonjol dari aplikasi ini adalah bahwa jurnal akuntansi dan laporan berada di bawah kontrol yang ketat dari pengguna.

2. Kurun 00s' termasuk dua kategori software akuntansi: "Integrasi" ditandai dengan aplikasi akuntansi menggunakan data yang disimpan secara lokal atau pada server - dan "SaaS" - ditandai dengan aplikasi multi-tenant berdasarkan database yang kuat disimpan di lokasi yang aman dan secara bersamaan diakses melalui internet oleh kedua klien dan akuntan.

3. Kurun 2010 - Hadir - dikenal sebagai periode software akuntansi "Mobile", penyebab adanya dashboard keuangan berbasis internet dan keberadaan aplikasi mobile yang melayani kebutuhan apapun kapanpun.

Bogdan et al. (2013) mengungkapkan adanya cost-saving yang dapat dihasilkan dari migrasi ke cloud accounting (Tabel 1) dengan mengklasifikasikan langkah-langkah dalam operasional akuntansi kemudian memberikan bobot pada setiap langkah tersebut. Selanjutnya akan dilakukan identifikasi apakah langkah-langkah operasional yang dilakukan dapat dialihkan ke cloud accounting. Bila dapat dialihkan, maka berikutnya akan diukur berapa persentase yang dapat dialihkan. Terakhir adalah kuantifikasi ke 


\begin{tabular}{|c|c|c|c|c|c|}
\hline \multirow[b]{2}{*}{ Steps: } & \multirow[b]{2}{*}{$\begin{array}{l}\text { Weight in } \\
\text { total annual } \\
\text { operations }\end{array}$} & \multirow[b]{2}{*}{$\begin{array}{l}\text { Possibility } \\
\text { of moving } \\
\text { to the } \\
\text { cloud }\end{array}$} & \multirow[b]{2}{*}{$\begin{array}{l}\text { Percentage } \\
\text { of moving to } \\
\text { the cloud }\end{array}$} & \multicolumn{2}{|c|}{ Cost saving generated by: } \\
\hline & & & & $\begin{array}{l}\text { Accounting } \\
\text { company }\end{array}$ & $\begin{array}{l}\text { Authorized } \\
\text { accountant }\end{array}$ \\
\hline $\begin{array}{l}\text { Setting out the } \\
\text { balance of } \\
\text { accounts prior to } \\
\text { inventory }\end{array}$ & $15 \%$ & YES & $100 \%$ & 103.5 & 90 \\
\hline $\begin{array}{c}\text { General inventory } \\
\text { of assets and } \\
\text { debts }\end{array}$ & $15 \%$ & NO & $0 \%$ & 0 & 0 \\
\hline $\begin{array}{l}\text { Checking the } \\
\text { accounts, ending' } \\
\text { balance }\end{array}$ & $10 \%$ & YES & $100 \%$ & 69 & 60 \\
\hline $\begin{array}{c}\text { Accruals } \\
\text { transactions }\end{array}$ & $10 \%$ & YES & $50 \%$ & 34.5 & 30 \\
\hline $\begin{array}{l}\text { Setting out the } \\
\text { balance of } \\
\text { accounts after the } \\
\text { inventory and } \\
\text { regulatory } \\
\text { operations }\end{array}$ & $10 \%$ & YES & $100 \%$ & 69 & 60 \\
\hline $\begin{array}{l}\text { Determining the } \\
\text { profit or loss, } \\
\text { profit distribution } \\
\text { or funding loss }\end{array}$ & $10 \%$ & YES & $100 \%$ & 69 & 60 \\
\hline $\begin{array}{l}\text { Setting out the } \\
\text { final balance of } \\
\text { accounts }\end{array}$ & $10 \%$ & YES & $100 \%$ & 69 & 60 \\
\hline $\begin{array}{l}\text { Accomplishing the } \\
\text { major financial } \\
\text { statements }\end{array}$ & $10 \%$ & YES & $100 \%$ & 69 & 60 \\
\hline $\begin{array}{l}\text { Accomplishing the } \\
\text { annexes to the } \\
\text { financial } \\
\text { statements }\end{array}$ & $10 \%$ & YES & $30 \%$ & 20.7 & 18 \\
\hline \multicolumn{4}{|c|}{ TOTAL } & 503.7 & 438 \\
\hline
\end{tabular}

Tabel 1 Penghematan Biaya karena Migrasi ke Cloud Accounting

unit moneter penghematan yang dihasilkan dari proses migrasi tersebut. Bogdan et al. (2013) menggunakan model perhitungan Return on Investment dari Misra dan Mondal (2010):

ROI for cloud $=\frac{\text { Increase in profits }+ \text { Reduction of costs }- \text { Cloud costs }}{\text { Cloud costs }}$

ROI tersebut menghitung total keseluruhan kenaikan keuntungan dan penghematan biaya bersih yang dihasilkan setelah dikurangi dengan biayabiaya KA dibanding dengan total biaya
KA. Bogdan et al. (2013) kemudian menggunakannya untuk menghitung ROI dalam penelitiannya untuk sistem yang memiliki 10,30 dan 50 pengguna.

\begin{tabular}{|l|cc|}
\hline \multicolumn{3}{|c|}{ Accounting company-10 users } \\
\hline \multicolumn{1}{|c|}{ Monthly } & Expert Accounts & e-contabilitate.ro \\
\hline Profit growth & 10 & 10 \\
Cost saving & 217.5 & 217.5 \\
Cloud related costs & 100 & 20 \\
ROI & 1.275 & 10.375 \\
\hline
\end{tabular}

Tabel 2 ROI untuk 10 Pengguna 


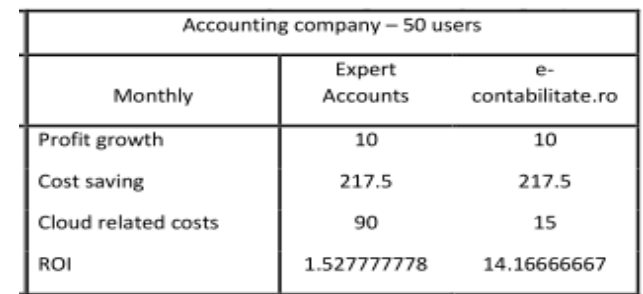

Tabel 4 ROI untuk 50 Pengguna

\begin{tabular}{|l|cc|}
\hline \multicolumn{3}{|c|}{ Accounting company - 30 users } \\
\hline \multicolumn{1}{|c|}{ Monthly } & Expert Accounts & e- \\
& contabilitate.ro \\
\hline Profit growth & 10 & 10 \\
Cost saving & 217.5 & 217.5 \\
Cloud related costs & 97 & 18 \\
ROI & 1.345360825 & 11.63888889 \\
\hline
\end{tabular}

Tabel 3 ROI untuk 30 Pengguna

Selain ROI, cara pembandingan kedua adalah menggunakan Total Cost of Ownership di mana secara sederhana menghitung semua biaya yang mungkin terjadi antara akuisisi sistem akuntansi tradisional dengan berbasis cloud.

\section{Sistem Informasi Akuntansi bagi UMKM di Indonesia}

Perkembangan UMKM di Indonesia mendapat perhatian khusus dari pemerintah lebih lanjut (Tabel 5). Untuk mendorong perkembangan UMKM dilakukan dengan meningkat- kan akses permodalan ke lembaga keuangan. Konsekuensinya adalah peningkatan akuntabilitas pelaporan keuangan UMKM sebagai dasar penilaian kinerja dan prospek bisnis usahanya.

Hasil penelitian Pinasti (2007) terhadap Pengusaha UMKM di Wilayah Provinsi Jawa Tengah menunjukkan bahwa penyelenggaraan dan penggunaan informasi akuntansi terbukti secara empiris mempunyai pengaruh terhadap persepsi pengusaha kecil atas informasi akuntansi. Atau dalam kata lain, ketika pengusaha kecil telah merasakan manfaat atas keberadaan informasi akuntansi maka mereka akan menganggap bahwa informasi akuntansi penting bagi mereka, namun sebaliknya selama pengusaha kecil tersebut tidak pernah menggunakan informasi akuntansi maka informasi akuntansi dianggap sesuatu yang tidak penting.

Namun demikian Rodhiyah (2012) menyatakan bahwa sebagian besar responden melakukan pencatatan keuangan secara sederhana dan tidak lengkap serta dikerjakan sendiri, yaitu dikerjakan oleh pemilik UKM. Alasan yang dikemukakan yaitu tidak ada waktu atau waktu terbatas, rumit, sulit.
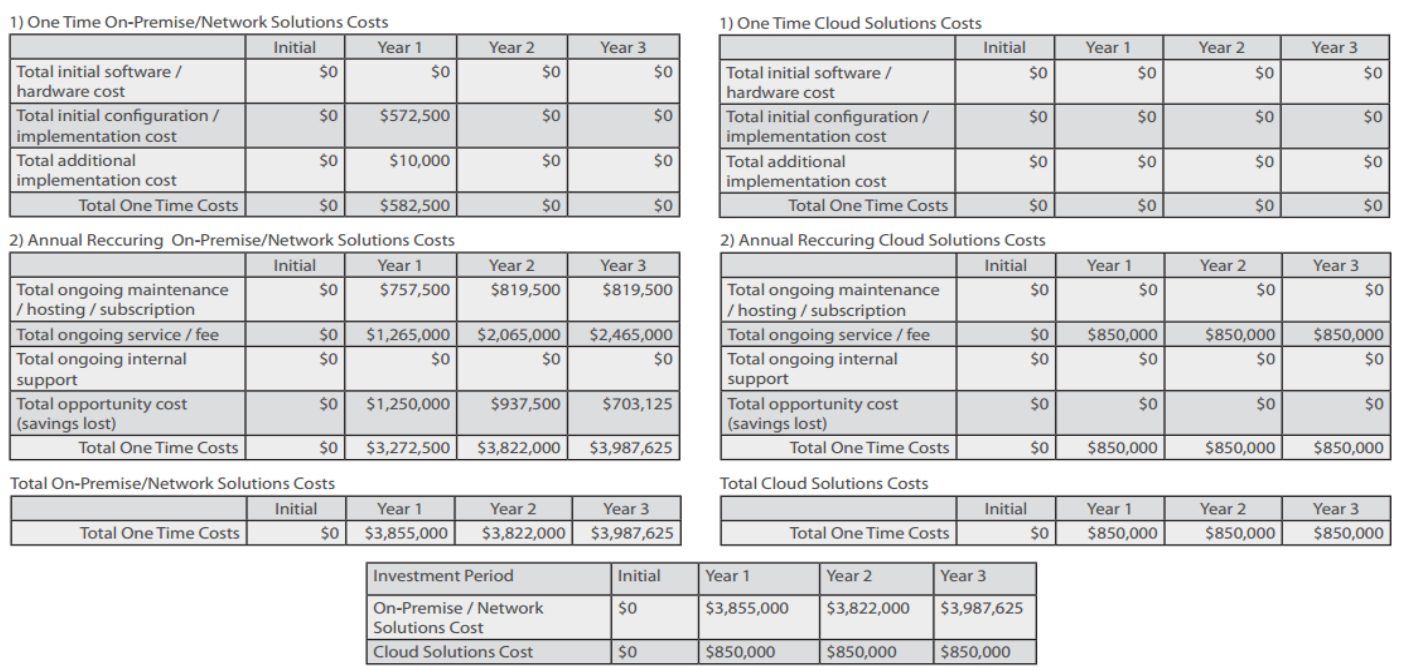

\begin{tabular}{|l|l|l|l|l|}
\hline Investment Period & Initial & Year 1 & Year 2 & Year 3 \\
\hline $\begin{array}{l}\text { On-Premise / Network } \\
\text { Solutions Cost }\end{array}$ & $\$ 0$ & $\$ 3,855,000$ & $\$ 3,822,000$ & $\$ 3,987,625$ \\
\hline Cloud Solutions Cost & $\$ 0$ & $\$ 850,000$ & $\$ 850,000$ & $\$ 850,000$ \\
\hline
\end{tabular}

Tabel 5 Perbandingan TCO 
Menurut mereka "yang penting saya mengerti dan paham dengan apa yang saya buat". Sedangkan ada sebagian kecil UKM yang membuat laporan keuangan lebih lengkap.

Berbagai catatan keuangan atau laporan keuangan yang dibuat dianggap sudah memadai dan cukup dipahami. Yang penting "kami paham dengan apa yang kami buat" (pendapat mereka) berkaitan dengan utang piutang, jumlah pesanan atau jumlah penjualan, kapan pesanan harus selesai, jumlah uang kas yang ada, pembayaran gaji pegawai dan keuntungan yang diperoleh. Aspek akuntabilitas penyusunan laporan keuangan berupa pencatatan keuangan dilakukan secara sederhana dan belum mengikuti sistem akuntansi, Hal ini disebabkan pengetahuan tentang pembukuan relatif kurang, tidak ada waktu, tidak ada tenaga dan merasa sulit serta rumit. Mereka menganggap bahwa penyelesaian kegiatan produksi lebih penting jika dibanding dengan pembukuan. Pencatatan keuangan yang dilakukan belum dapat dipakai sebagai laporan kinerja keuangan. Akibatnya tidak bisa digunakan untuk memprediksi kegiatan usaha maupun sebagai pertanggung- jawaban kepada pihak-pihak terkait.

Saat ini telah diterbitkan SAK baru khusus untuk ETAP (Entitas Tanpa Akuntabilitas Publik) dalam rangka pengembangan standar akuntansi yang dapat digunakan oleh UMKM sebagai acuan. SAK ETAP merupakan SAK yang berdiri sendiri dan tidak mengacu pada SAK Umum. Sebagian besar menggunakan konsep biaya historis; mengatur transaksi yang dilakukan oleh ETAP; bentuk pengaturan yang lebih sederhana dalam hal perlakuan akuntansi dan relatif tidak berubah selama beberapa tahun. Penggunaannya ditujukan untuk entitas tanpa akuntabilitas publik, dimana entitas tanpa akuntabilitas publik berdasarkan SAK ETAP Bab 1 Paragraf 1 adalah entitas yang: 1) tidak memiliki akuntabilitas publik signifikan; dan 2) menerbitkan laporan keuangan untuk tujuan umum (general purpose financial statement) bagi pengguna eksternal.

\section{METODE PENELITIAN}

Penelitian ini bersifat deskriptif analitik untuk memahami dan membandingkan kelebihan dan kekurangan penggunaan sistem informasi akun-

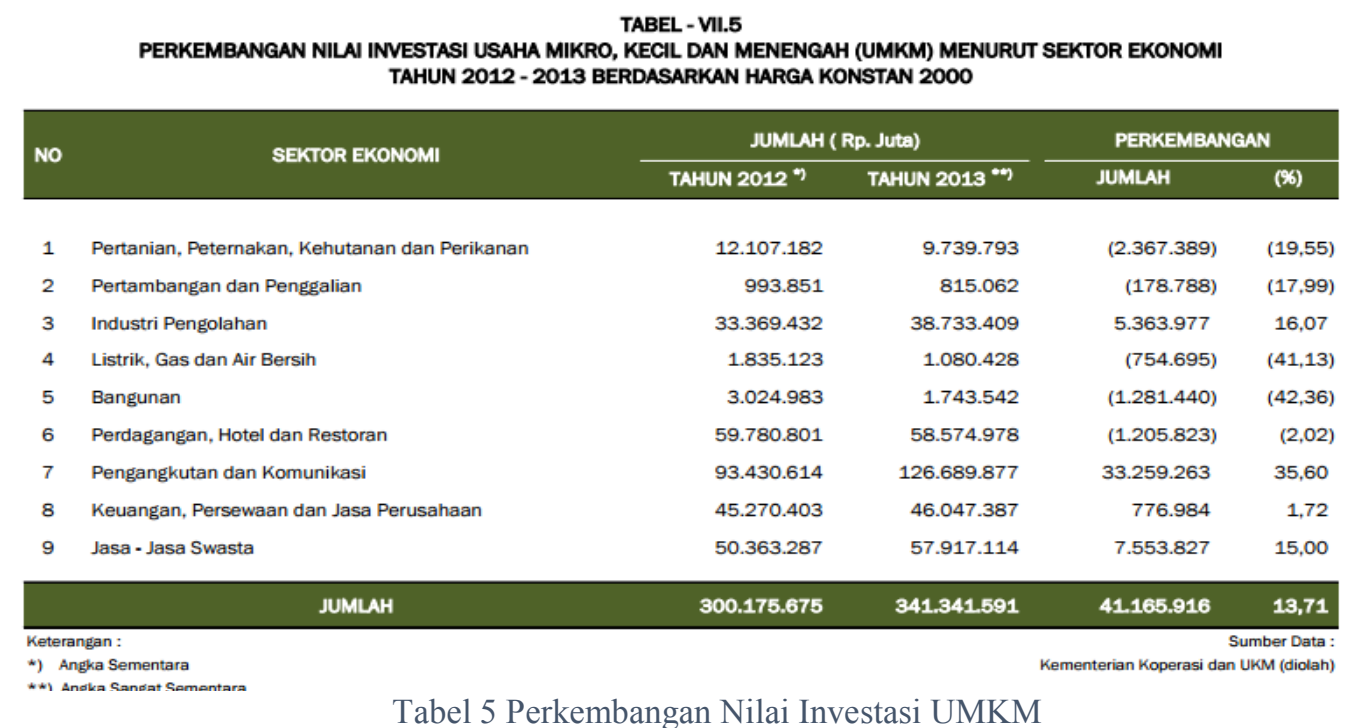


tansi di lingkungan komputasi awan dengan menganalisis berbagai faktor dari hasil penelitian, jurnal dan teoriteori yang menyebabkan komputasi awan menjadi kecenderungan seiring dengan perkembangan teknologi informasi dibandingkan dengan mengambil contoh paket sistem informasi tidak berbasis komputasi awan tersedia, dijual dan memiliki kantor layanan purna jual di Surabaya yang memiliki target market para pemilik dan manajemen usaha kecil dan menengah yaitu Bee Accounting dan Omega Accounting. Keduanya memiliki modul-modul dasar dan fitur-fitur dasar yang sama serta memiliki opsi implementasi berbasis KA (SaaS) maupun solusi instalasi non-KA agar dapat dengan mudah dibandingkan.

\section{PEMBAHASAN}

Secara umum paket sistem informasi akuntansi tersedia di Surabaya dengan target pasar pemilik dan manajemen UMKM yang berkantor pusat di Surabaya yaitu Bee Accounting dan Omega Accounting memiliki modulmodul dasar sebagai berikut:

1. Modul Pembelian (purchase order hingga inbound logistics termasuk retur dan pengelolaan $\mathrm{A} / \mathrm{P})$.

2. Modul Penjualan (sales order hingga outbound logistics termasuk retur dan pengelolaan $\mathrm{A} / \mathrm{R})$.

3. Modul Inventory (costing, konversi, transfer dan opname).

4. Modul Kas dan Bank.

5. Modul Fixed Assets.

6. Modul Jurnal Umum.

Di samping itu ada modul-modul tambahan berikut ini:

1. Modul Kasir Point of Sale.

2. Modul Manajemen Proyek.

3. Modul PPN.
Baik modul-modul dasar maupun tambahan tersedia juga di versi berbasis KA dengan tambahan fitur-fitur unggulan yang sepenuhnya memanfaatkan kelebihan fleksibilitas KA berupa:

\section{Realtime.}

2. Online.

3. Multi-platform.

4. Virtual backup.

5. Kecepatan setup.

Menurut Ceslovas dan Miseviciene (2012) pemilik dan manajemen UMKM perlu mempertimbangkan beberapa resiko agar dapat membandingkan kelebihan-kelebihan yang bersifat finansial maupun non-finansial dan kekurangan serta risiko-risiko kualitatif (Tabel 6). Implementasi sistem informasi akuntansi berbasis KA di samping itu perlu mempertimbangkan faktor-faktor biaya tambahan. Faktor-faktor finansial tersebut dapat digunakan dengan membandingkan dua metode:

1. Pertama, ROI dari akuisisi aplikasi akuntansi tradisional dengan ROI implementasi cloud accounting.

2. Kedua, perbandingan TCO antara kedua alternatif tersebut. Periode yang dijadikan acuan adalah masa manfaat kelompok satu (empat tahun) sesuai yang tertuang dalam Keputusan Dirjen Pajak (KEP) No. 316/PJ/2002 Tentang Perlakuan Pajak Penghasilan/Biaya Perolehan Perangkat Lunak Komputer (Software).

Sedangkan faktor-faktor kualitatif seperti risiko dapat kemudian diberikan bobot sesuai dengan karakteristik usaha dan lokasi masing-masing UMKM agar bisa dikuantifisir dan dibandingkan dengan mudah antara akuisisi aplikasi akuntansi dan implementasi cloud accounting. 
Risks of cloud computing to business

\begin{tabular}{|l|l|}
\hline \multicolumn{1}{|c|}{ Risks } & \multicolumn{1}{|c|}{ Explanation and characteristics } \\
\hline Fear for safety & $\begin{array}{l}\text { * cloud computing can also bring substantial risks } \\
\text { in the privacy and confidentiality areas. } \\
\text { * main concentration in accounting is money } \\
\text { managing; so cloud computing would not be an } \\
\text { ideal because some of the most important } \\
\text { information, such as bank accounts, are less secure. }\end{array}$ \\
\hline $\begin{array}{l}\text { Internet } \\
\text { failures }\end{array}$ & $\begin{array}{l}\text { " if internet is down then the accountant can not } \\
\text { access information directly. } \\
\text { * in the accounting profession, accountants want to } \\
\text { have access to their information at any or every } \\
\text { given time. }\end{array}$ \\
\hline Control loss & $\begin{array}{l}\text { " company loses control over the software } \\
\text { application and become dependent on the provider } \\
\text { to maintain, update and manage it. }\end{array}$ \\
\hline Dependency & $\begin{array}{l}\text { * company becomes dependent on a cloud-based } \\
\text { software application. }\end{array}$ \\
\hline
\end{tabular}

Tabel 6 Resiko-resiko Komputasi Awan

\section{KESIMPULAN}

Penelitian ini menunjukkan bahwa di samping kelebihan-kelebihan Sistem Informasi Akuntansi berbasis Cloud terdapat beberapa hal NonCloud yang harus dipertimbangkan seperti risiko-risiko yang dihadapi, tambahan investasi dan biaya-biaya operasional bagi pemilik usaha dan manajemen UMKM.

\section{SARAN}

Setelah penelitian ini, agar didapatkan gambaran lebih baik dan kontekstual mengenai sistem informasi akuntansi yang dibutuhkan, diperlukan penelitian lanjutan mengenai:

1. Persepsi para pemilik dan manajemen UMKM lokal atas penerapan sistem informasi akuntansi berbasis komputasi awan.
2. Integrasi dengan fungsi-fungsi organisasi lain yang dianggap penting bagi para pemilik dan manajemen UMKM lokal.

3. Penelitian kuantitatif mengenai perbandingan ROI atau TCO kedua solusi tersebut pada masing-masing usaha.

4. Penelitian kuantitatif mengenai perbandingan antara biaya dan manfaat implementasi kedua solusi tersebut pada masing-masing usaha.

\section{DAFTAR KEPUSTAKAAN}

Andru, Peter and Alexei Botchkarev, 2011, A Return on Investment as a Metric for Evaluating Information Systems: Taxonomy and Application, Interdisciplinary Journal of Information, Knowledge and Management, Vol. 6. 
Bagian Data-Biro Perencanaan, 2014, Statistik Usaha Mikro, Kecil dan Menengah (UMKM) Tahun 2012 2013, Kementrian Koperasi dan UKM, Jakarta.

Bogdan, Ionescu, Ionescu Iuliana, Bendovschi Andreea and Tudoran Laura, 2013, Traditional Accounting vs Cloud Accounting, Research Gate, www.researchgate.net.

Castellina, Nick, 2014, Don't Sweat The Details: Use Accounting Software and Focus on Growing Your Business, Business Planning and Execution Aberdeen Group, Boston

Ceslovas, Christauskas, and Regina Miseviciene, 2012, Cloud-Computing Based Accounting for Small to Medium Sized Business, Inzinerine Ekonomika-Engineering Economics, 23 (1), Kaunas.

Columbus, Louis, 2016, Roundup Of Cloud Computing Forecasts And Market Estimates, Forbes, www. forbes.com/sites/louiscolumbus/201 6/03/13/roundup-of-cloudcomputing-forecasts-and-marketestimates-2016/\#7dedd90274b0.

Kondo, Derrick Bahman Javadi, Paul Malecot, Franck Cappello and David P. Anderson, 2009, CostBenefit Analysis of Cloud Computing versus Desktop Grids, Proceedings of the 2009 IEEE International Symposium on Parallel \& Distributed Processing, Washington.

Lutfiaazahra, Alifta, 2015, Implementasi Standar Akuntansi Keuangan Entitas Tanpa Akuntabilitas Publik pada UMKM Pengrajin Batik
Laweyan Surakarta, Prosiding Seminar Nasional Pendidikan Ekonomi \& Bisnis, Fakultas Keguruan dan Ilmu Pendidikan Universitas Sebelas Maret, Surakarta.

Mell, Peter and Timothy Grance, 2011, NIST Special Publication 800-145: NIST Definition of Cloud Computing, Computer Security Division Information Technology Laboratory-National Institute of Standards and Technology, Gaithersburg.

Paystream Advisor, 2012, Calculate Your Total Cost of Ownership: Cloud vs. On-Premise/Network Solutions, Paystream Advisors Research Report Q3-2012, Charlotte.

Phillips, Bruce A, 2012, How Cloud Computing Will Change Accounting Forever, Harsman Phillips, Atlanta.

Pinasti, Margani, 2007, Pengaruh Penyelenggaraan dan Penggunaan Informasi Akuntansi Terhadap Persepsi Pengusaha Kecil atas Informasi Akuntansi: Suatu Riset Eksperimen, Jurnal Riset Akuntansi Indonesia, Vol. 10, No. 3, Fakultas Ekonomi, Universitas Hasanuddin, Makassar.

Rodhiyah, 2012, Kajian Tentang Akuntabilitas Usaha Kecil Menengah Melalui Laporan Keuangan (Studi Kasus Pada UKM Konveksi di Semarang), Universitas Diponegoro, Semarang.

Romney, Marshall B. and Paul J. Steinbart, 2012, Accounting Information System, Pearson Higher Education, Edinburg Gate-Harlow. 
Simkin, Mark. J., Jacob. M. Rose and Norman Strand Carolin, 2012, Core Concept of Accounting Information System, $12^{\text {nd }}$ Edition, John Wiley \& Sons, Inc., Jefferson City.

Stieningera, Mark, Dietmar Nedbala, Werner Wetzlingera, Gerold Wagnera and Michael A. Erskineb, 2014, Impacts on The Organizational Adoption of Cloud Computing: A reconceptualization of Influencing Factors, Procedia Technology, www.sciencedirect.com.
Syaikhu, Akhmad, 2010, Komputasi Awan (Cloud Computing) Perpustakaan Pertanian, Jurnal Pustakawan Indonesia, Vol. 10, No. 1, Institut Pertanian Bogor, Bogor. 